ARTIGOS

\title{
OS PLANOS CURRICULARES DE CURSOS EM SUPERVISÃO: UM CONTRIBUTO PARA UMA EPISTEMOLOGIA DA PRÁTICA
}

\author{
Jane do Carmo MACHADO \\ Universidade de Aveiro - UA - Departamento de Educação \\ e Psicologia - Centro de Investigação em Didática e Tecnologia na Formação \\ de Formadores - CIDTFF - Aveiro, Portugal \\ janemachado@ua.pt \\ https://orcid.org/0000-0001-8786-4108
}

Ana Isabel ANDRADE Universidade de Aveiro - UA - Departamento de Educação e Psicologia Centro de Investigação em Didática e Tecnologia na Formação de Formadores - CIDTFF - Aveiro, Portugal aiandrade@ua.pt https://orcid.org/0000-0002-3182-9351

Rui NEVES

Universidade de Aveiro - UA - Departamento de Educação e Psicologia Centro de Investigação em Didática e Tecnologia na Formação de Formadores - CIDTFF - Aveiro, Portugal https://orcid.org/0000-0002-3285-7733 rneves@ua.pt

Resumo: Este estudo tem por objetivo apresentar uma reflexão sobre as possibilidades de construção de uma epistemologia da prática supervisiva a partir da análise da formação na área da supervisão, com incidência sobre os planos curriculares de cursos de Mestrado em Supervisão das Instituições de Ensino Superior (IES) Portuguesas. O estudo fundamenta-se em três perspetivas conceptuais orientadoras da ação supervisiva: i) a ação supervisiva como transformadora e emancipatória; ii) a articulação entre desenvolvimento profissional e interação colaborativa; iii) a supervisão e a construção de uma epistemologia da prática. Face às semelhanças dos planos curriculares de diversas Instituições de Ensino Superior Portuguesas em relação ao conteúdo programático, podemos sustentar que se defende uma proposta que oferece aos profissionais uma visão do campo da supervisão no terreno da prática, propiciando um espaço de desenvolvimento profissional a partir da reflexão sobre a prática educativa e/ou formativa.

Palavras-chave: Plano curricular.supervisão.epistemologia da prática supervisiva.formação. 


\title{
autêntica
}

\section{THE CURRICULAR PLANS OF MASTERS IN SUPERVISION:A CONTRIBUTION TO THE EPISTEMOLOGY OF PRACTICE}

\begin{abstract}
This text aims to present a study on the possibilities of building an epistemology of supervisory practice from the analysis of training in the area of supervision, focusing on the curricular plans of Masters in Supervision of Portuguese Higher Education Institutions (HEI). The study is based on three guiding conceptual perspectives of supervisory action: i) supervisory action as transformative and emancipatory; ii) the articulation between professional development and collaborative interaction; iii) the supervision and construction of an epistemology of practice. Due to the similarities in the curriculum plans of several Portuguese Higher Education Institutions in relation to the content, we can argue that their proposal offers the professionals a vision of supervision in the field of practice, providing a space for professional development based on a reflection on educational and / or formative practice.
\end{abstract}

Keywords: Curricular plan. supervision. epistemology of supervisory practice. training.

\section{LES PLANS CURRICULAIRES DES MASTERS EN SUPERVISION: UNE CONTRIBUTION À L’ÉPISTÉMOLOGIE DE LA PRATIQUE}

Résumé: Ce texte vise à présenter une étude sur les possibilités de construire une épistémologie de la pratique de la supervision à partir de l'analyse de la formation dans ce domaine, tout en ayant comme focus les plans curriculaires des masters en supervision des établissements d'Enseignement Supérieur Portugais. L'étude se base sur trois perspectives conceptuelles qui guident l'action de surveillance: i) I'action de surveillance comme transformatrice et émancipatrice; ii) l'articulation entre le développement professionnel et l'interaction collaborative; iii) l'encadrement et la construction d'une épistémologie de la pratique. Compte tenu des similitudes des plans curriculaires de plusieurs établissements d'Enseignement Supérieur Portugais en ce qui concerne les programmes, nous pouvons affirmer qu'il y a une proposition qui est visible: I'offre aux professionnels d'une perspective de la supervision dans le domaine de la pratique, comme un espace de développement professionnel basé sur la pratique éducative et/ou de formation.

Résumé - mots-clés: Plan curriculaire. supervision. épistémologie de la pratique de supervision. formation. 


\section{Introdução}

A supervisão como campo do conhecimento na área educacional exige que sejam observadas as suas múltiplas dimensões, especialmente a que está diretamente relacionada ao lugar por ela ocupado com vista à melhoria da prática pedagógica de professores e às inúmeras possibilidades de desenvolvimento profissional a partir do trabalho realizado. Pensar a dimensão formação e o trabalho educativo implicados na ação supervisiva leva a alguns questionamentos que podem contribuir para o desenvolvimento da argumentação-reflexão neste estudo. Nesse sentido, apresentamos três questionamentos que têm como pano de fundo a supervisão como campo do conhecimento, o que pressupõe observação-reflexão-ação-colaboração, a saber:
I) A prática supervisivaapresenta-se como transformadora e emancipatória?
II) É possível equacionar desenvolvimento profissional, interação colaborativa e supervisão?
III) Qual a epistemologia que está presente na prática supervisiva?

Assim, neste estudo, considerando esses questionamentos, intencionamos, no desenvolvimento da argumentação-reflexão, apontar algumas pistas que possam contribuir para a compreensão da complexidade da ação supervisiva a partir da análise dos Planos curriculares das Instituições de Ensino Superior Portuguesas no que tange à formação de profissionais em cursos de Mestrado em Supervisão.

Ação supervisiva na prática pedagógica: possibilidades de transformação

Tal como Vieira (2009), entendemos a pedagogia como objeto da supervisão. Para esta autora, a supervisão e a pedagogia possuem uma componente conceptual e outra experiencial, que se constituem como práxis. Se a supervisão assume uma dimensão de acompanhamento da prática pedagógica, esta tem a possibilidade de ser observada, avaliada e redirecionada a partir do diálogo, da escuta ativa, o que lhe imprime um movimento de transformação do fazer e do pensar sobre esse mesmo fazer. Assim, quando o status quo sofre alteração e o sujeito, formando (educador ou professor em formação), consegue vislumbrar outros caminhos para o desenvolvimento de sua ação docente, não só se transforma a si próprio, como se abre a possibilidade para a transformação e a mudança de seus pares e dos contextos, tornando possível, portanto, que a prática pedagógica (e docente) se constitua como uma atividade emancipatória.

Ao sustentarmos que a supervisão permite uma regulação da qualidade da pedagogia como condição de compreensão e renovação (ALARCÃO; TAVARES, 2010; ALARCÃO, 2010a; 2010b; VIEIRA, 2009; VIEIRA; MOREIRA, 2011; SÁ-CHAVES, 2011), atribuímos à supervisão um papel determinante na melhoria da qualidade da ação pedagógico-educativa. Tal atribuição imputa ao profissional supervisor uma responsabilidade e um compromisso no processo de acompanhamento de formandos e/ou de outros profissionais que sejam capazes de fazer com que eles próprios se possam reconhecer como supervisores da sua própria atividade docente, segundo uma perspetiva de quem olha com intenção de melhorar e ressignificar os processos de educação e formação. Nessa linha, se tem vindo a sustentar que a supervisão tem de ser de natureza transformadora e de orientação emancipatória, devendo fundamentar-se em valores democráticos de liberdade e de responsabilidade social e permitindo avançar para a conquista de práticas pedagógicas mais significativas para os sujeitos que as vivem.

Assim, os princípios reguladores de uma prática supervisiva de natureza transformadora e de orientação emancipatória, defendidos por diferentes autores, entre os quais Vieira (2009), exigem dos profissionais supervisores e dos supervisionados a assunção de um discurso problematizador-ativo, que potencie uma 
evolução no pensar e no agir, considerando o lugar em que esses sujeitos se encontram e afastando o discurso da passividade que coloca esses sujeitos como meros recetores de outros discursos (MACHADO, 2012, 2015). Neste sentido, se constitui como finalidade última da supervisão a formação de profissionais de educação autónomos, capazes de pensar e agir por si próprios, sabendo que a sua aprendizagem se realiza em interação com os outros e consigo próprios, em processos de auto e/ou de hétero supervisão da prática pedagógica.

Desenvolvimento profissional, interação colaborativa e supervisão

Segundo Alarcão (2014), a opção pelo termo interação colaborativa decorre da indissociabilidade dos dois termos, isto porque na interação se constrói algo de modo colaborativo. A autora destaca doze características presentes em uma ação de interação colaborativa, optando nós, neste estudo, por agrupá-las em três orientações consideradas presentes nessas doze características: reconhecimento do desenvolvimento permanente do par como sujeito e profissional; validação constante da partilha; e visão conjunta das limitações e das potencialidades de cada ação/projeto, tendo em conta o papel assumido por cada um. Tal agrupamento é feito com a intenção de trazer para o centro da discussão o aspecto tempo-movimento de toda ação humana que pode transformar cada sujeito nas interações em que participa. Desse modo, tal perspetiva aponta para um movimento que pode levar os sujeitos envolvidos não só a se perceberem como supervisores de suas próprias ações como também das dos seus pares, responsabilizando-se pelo seu próprio desenvolvimento profissional e pelo do outro.

Neste prisma, sustentamos, de acordo com a perspetiva de Alarcão (2014), que há um elo que une desenvolvimento profissional, interação colaborativa e supervisão, cuja intencionalidade é atribuir significado às ações propostas pelo sujeito tanto individual como coletivamente, e que, na dimensão da sua profissionalidade, se encontram intimamente relacionadas. Se há uma relação entre o que é individual e pessoal no sujeito que tem implicações no coletivo, isso tem repercussões nos modos como a atividade docente é percebida, especialmente, considerando-se a sua complexidade. A complexidade presente na ação docente está relacionada aos espaços-tempos, aos acompanhamentos, às concepções, reflexões, limitações, continuidades, rupturas e potencialidades dos sujeitos e dos contextos envolvidos em um movimento que precisa ser permanentemente construído e ressignificado.

Epistemologia da prática supervisiva: construída na formação e no trabalho?

Se a supervisão tem como grande intenção a transformação da prática pedagógica dos sujeitos, ela inscreve-se no trabalho e este deve inscrever-se na formação. Embora pareçam ocupar espaços distintos, esses espaços não só convergem, como se interinfluenciam, o que exige uma ação de acompanhamento, que coloque os sujeitos supervisores a transitarem entre os dois espaços conferindo-lhes um caráter de unidade. Nessa perspetiva, podemos pensar no conceito de terceiro espaço, espaços híbridos, em que o conhecimento acadêmico junta-se ao prático para em conjunto poderem superar hierarquias tradicionalmente validadas, transformar e criar novas oportunidades de aprendizagem mais integradas (ZEICHNER, 2010).

Essa unidade leva a pensar que a formação desarticulada do trabalho esvazia-se de sentido e o trabalho sem vínculo com a formação desqualifica o sujeito que ensina e aprende e o que aprende e ensina ao mesmo tempo. Esse movimento entre os sujeitos e os contextos, sustentado por saberes, experiências e partiIhas com os pares, é capaz de contribuir para a construção de uma epistemologia da prática supervisiva. Essa epistemologia da prática supervisiva revela-se por meio do acompanhamento da prática docente de 


\section{autêntica}

DOI https://doi.org/10.31639/rbpfp.v12i24.314

professores em formação e de professores em pleno exercício da atividade docente no terreno privilegiado da prática, a escola.

A epistemologia da prática supervisiva coloca o profissional supervisor em sintonia com a natureza própria do seu trabalho, o que demanda um processo reflexivo, avaliativo e crítico de modo a proporcionar a construção de um repertório epistemológico capaz de responder a necessidades oriundas desse fazer.

Na construção de uma epistemologia da prática supervisiva, deve ser possível ao supervisor defender um estatuto da profissão capaz de conferir e de legitimar um lugar essencial no acompanhamento da formação e do trabalho pedagógico dos professores, tornando sua ação-intervenção credível, pois fundamentada de modo a poder compreender a complexidade da docência e suas implicações para os que ensinam, aprendendo, os professores, e os que aprendem, ensinando, os alunos.

Nessaperspetiva, não é o supervisor que define os rumos da prática pedagógica, mas ele é detentor de uma epistemologia da práticasupervisiva, decide junto com os professores o que deve ser feito para que o processo ensino-aprendizagem tenha qualidade e se conquistem os objetivos traçados, assim como os professores tenham oportunidades de desenvolvimento profissional a partir da articulação formação-trabalho.

Da formação em Supervisão ao trabalho do supervisor

Na sequência do exposto, importa pensar sobre os processos de formação ao nível dos cursos de Mestrado com vista a identificar as possibilidades de articulação formação-trabalho quando se tem como pressuposto a construção de uma epistemologia da prática supervisiva.

Na formação de profissionais supervisores, em nível dos cursos de Mestrado, as Instituições de Ensino Superior Portuguesas (IES) elaboram os seus planos de estudos com componentes curriculares que versam sobre o campo de investigação em educação e em supervisão e suas implicações para o processo de ensino e de aprendizagem, o funcionamento, a estruturação e a avaliação das organizações de ensino, o desenvolvimento profissional de professores e de supervisores, a supervisão pedagógica e a avaliação do desempenho de professores. Face às semelhanças apresentadas nos planos curriculares de diversas instituições de ensino portuguesas, é possível sustentar a defesa de uma proposta que ofereça ao futuro profissional uma visão do campo da supervisão ligada ao terreno da prática supervisiva, cujo aprofundamento das questões decorrerá do exercício dessa atividade.

Nessa linha, apresentamos um quadro, na metodologia, composto pelas IES portuguesas que oferecem o Mestrado para formação de supervisores, destacando-se alguns aspetos considerados importantes nessa formação desde o objetivo geral dos cursos até aos planos de ensino. No que tange à legislação - Artigo $23^{\circ}$ do Decreto-Lei n 79 de 2014 - (PORTUGAL, 2014) que regula, de algum modo, o trabalho dos supervisores, exige-se, pelo menos ao nível da formação inicial de professores, experiência na atividade profissional docente de pelo menos 5 anos e recomenda-se formação pós-graduada na área de docência ou na área da supervisão.

\section{Metodologia}

O estudo aqui apresentado, de natureza qualitativa e de caráter exploratório, centrou-se em uma análise documental a partir de levantamento inicial na página principal dos Web sites de 27 IES portuguesas para identificar as que oferecem o curso de Mestrado em Supervisão, tendo sido identificadas 13. Das 13 


\section{autêntica}

DOI https://doi.org/10.31639/rbpfp.v12i24.314

instituições que oferecem cursos em Supervisão, 1 oferece o curso em duas especialidades na modalidade a distância. Das 13 instituições identificadas, $7\left({ }^{*}\right)$ não disponibilizam os conteúdos presentes nas unidades curriculares do Plano de estudos, $5{ }^{* *}$ ) disponibilizam todo o programa das unidades curriculares (conteúdos programáticos, objetivos, metodologia de ensino e de avaliação, bibliografia...), $1\left(^{* * *}\right)$ disponibiliza apenas os temas a tratar no curso e todas as instituições apresentam o quantitativo de ECTS (Sistema Europeu de Transferência e Acumulação de Créditos) para cada componente curricular, atribuindo, no segundo ano do curso, um quantitativo de pelos menos 30 ECTS ao projeto/dissertação, de acordo com a legislação em vigor - Decreto-Lei nº 74/2006, de 24 de março, alterado pelo Decreto-Lei no 107/2008, de 25 de junho, Decreto-Lei n 230/2009, de 14 de setembro e Decreto-Lei n 115/2013, de 7 de agosto (PORTUGAL, 2006). As unidades curriculares presentes nos Planos de Estudos das 13 instituições são organizadas com maior ou menor peso da componente investigativa, mas sempre concedendo um papel de relevo à unidade curricular de Supervisão na estruturação do programa de ensino.

O tratamento dos dados decorrentes dos Planos de estudos das 13 IES portuguesas que oferecem o curso de Mestrado em Supervisão ancora-se na apresentação e na organização dos seguintes itens: nome da instituição, área, especialidade, objetivos, sendo que estes são objeto de análise mais aprofundada neste estudo.

Quadro 1 - Área e especialidades

IES -MESTRADOS EM SUPERVISÃO E COMO ESPECIALIDADES

\begin{tabular}{|c|c|c|}
\hline Instituição & Mestrado em: & Especialidade em: \\
\hline $\begin{array}{c}\text { Universidade de Aveiro - } \\
\text { Departamento de Educação e } \\
\text { Psicologia ** }\end{array}$ & Educação e Formação & Supervisão \\
\hline $\begin{array}{l}\text { Universidade de Lisboa - Instituto } \\
\text { de Educação ** }\end{array}$ & Educação & $\begin{array}{c}\text { Supervisão e Orientação da } \\
\text { Prática Profissional }\end{array}$ \\
\hline \multirow{2}{*}{$\begin{array}{l}\text { Universidade do Minho - Instituto } \\
\text { de Educação ** }\end{array}$} & \multirow{2}{*}{ Ciências da Educação } & $\begin{array}{l}\text { Supervisão Pedagógica na } \\
\text { Educação em Línguas (EAD) }\end{array}$ \\
\hline & & $\begin{array}{l}\text { Supervisão Pedagógica na } \\
\text { Educação em Ciências (EAD) }\end{array}$ \\
\hline $\begin{array}{l}\text { Universidade de Trás-os-Montes e } \\
\quad \text { Alto Douro (UTAD) * }\end{array}$ & Ciências da Educação & Supervisão Pedagógica \\
\hline Universidade de Évora *** & Ciências da Educação & Supervisão Pedagógica \\
\hline Universidade de Coimbra ** & $\begin{array}{l}\text { Supervisão Pedagógica e } \\
\text { Formação de Formadores }\end{array}$ & \\
\hline Universidade da Madeira * & Ciências da Educação & Supervisão Pedagógica \\
\hline $\begin{array}{c}\text { Universidade Católica Portuguesa } \\
\text { do Porto * }\end{array}$ & Ciências da Educação & $\begin{array}{l}\text { Supervisão Pedagógica e } \\
\text { Avaliação de Docentes }\end{array}$ \\
\hline
\end{tabular}




\section{autêntica}

DOI https://doi.org/10.31639/rbpfp.v12i24.314

\begin{tabular}{|c|c|c|}
\hline Universidade Lusófona do Porto ** & Ciências da Educação & $\begin{array}{c}\text { Supervisão Pedagógica e } \\
\text { Formação de Formadores }\end{array}$ \\
\hline $\begin{array}{c}\text { Instituto Politécnico do Porto - } \\
\text { Escola Superior de Educação * }\end{array}$ & $\begin{array}{c}\text { Supervisão em Educação } \\
\text { (b-Learning) }\end{array}$ & \\
\hline $\begin{array}{c}\text { Instituto Politécnico de Castelo } \\
\text { Branco - Escola Superior de } \\
\text { Educação * }\end{array}$ & $\begin{array}{c}\text { Supervisão e Avaliação } \\
\text { Escolar }\end{array}$ & \\
\hline $\begin{array}{c}\text { Instituto Politécnico de Viana } \\
\text { do Castelo - Escola Superior de } \\
\text { Educação * }\end{array}$ & Supervisão Pedagógica & \\
\hline $\begin{array}{c}\text { Instituto Politécnico de Lisboa - } \\
\text { Escola Superior de Educação * }\end{array}$ & $\begin{array}{c}\text { Supervisão em Educação } \\
\text { (Pós-Profissionalizante) }\end{array}$ & \\
\hline
\end{tabular}

Fonte: Os autores.

(*) não disponibilizam os conteúdos das unidades curriculares

$\left({ }^{*}\right)$ disponibilizam todo o programa das unidades curriculares

$\left({ }^{* *}\right)$ disponibiliza apenas os temas das unidades curriculares

Dos objetivos: algumas aproximações

As 13 IES portuguesas foco deste estudo apresentam objetivos diversos para os cursos de Mestrado em Supervisão que apontam para o modo como concebem a proposta de formação por cada uma privilegiada. Para compreender a base epistemológica em que estes objetivos estão alicerçados, optamos por fazer a leitura dos dados a partir de três perspetivas conceituais orientadoras da ação supervisiva: i) a ação supervisiva como transformadora e emancipatória; ii) a articulação entre desenvolvimento profissional e interação colaborativa; iii) e supervisão e construção de uma epistemologia da prática. Vejamos cada uma delas em particular.

Ação supervisiva como transformadora e emancipatória 


\section{autêntica}

DOI https://doi.org/10.31639/rbpfp.v12i24.314

Quadro 2 - Instituições e objetivos na ação supervisiva transformadora e emancipatória

\begin{tabular}{|c|c|}
\hline DAS INSTITUIÇÕES & DOS OBJETIVOS \\
\hline $\begin{array}{l}\text { Universidade de Aveiro - } \\
\text { Departamento de Educação e } \\
\text { Psicologia }\end{array}$ & $\begin{array}{c}\text { Formar profissionais capazes de contribuir ativamente para a } \\
\text { resolução dos diferentes problemas educativos com que se } \\
\text { debate a sociedade, através do estudo aprofundado, da prática da } \\
\text { investigação e da inovação educacional. }\end{array}$ \\
\hline \multirow{3}{*}{$\begin{array}{l}\text { Universidade do Minho - } \\
\text { Instituto de Educação }\end{array}$} & $\begin{array}{l}\text { Aplicar conhecimentos na resolução de problemas educativos do } \\
\text { âmbito da sua área de especialização. }\end{array}$ \\
\hline & $\begin{array}{l}\text { Integrar conhecimentos de modo a poder intervir em contextos } \\
\text { multidisciplinares, mesmo que indiretamente relacionados com a } \\
\text { sua área de especialização. }\end{array}$ \\
\hline & $\begin{array}{l}\text { Implementar projetos de investigação que contribuam para a } \\
\text { evolução de conhecimento na sua área de especialização. }\end{array}$ \\
\hline $\begin{array}{l}\text { Universidade de Trás-os-Montes } \\
\text { e Alto Douro (UTAD) }\end{array}$ & $\begin{array}{l}\text { Refletir criticamente sobre fenómenos de educação e } \\
\text { formação para perspetivar formas de investigação e de ação } \\
\text { sobre os mesmos. }\end{array}$ \\
\hline Universidade de Coimbra & $\begin{array}{l}\text { Desenvolver uma cultura de inovação pedagógica susceptível de } \\
\text { aplicação nas práticas educativas de ensino e de formação. }\end{array}$ \\
\hline $\begin{array}{l}\text { Instituto Politécnico de Castelo } \\
\text { Branco - ESSE }\end{array}$ & $\begin{array}{l}\text { Perspetivar criticamente processos de supervisão, observação e } \\
\text { avaliação pedagógica e institucional. }\end{array}$ \\
\hline $\begin{array}{l}\text { Instituto Politécnico de } \\
\text { Lisboa-ESSE }\end{array}$ & $\begin{array}{l}\text { Proporcionar o aprofundamento do conhecimento teórico e prático } \\
\text { no domínio da Supervisão em Educação para que os formandos } \\
\text { desenvolvam competências de avaliação, inovação e supervisão } \\
\text { adequadas aos contextos institucionais. }\end{array}$ \\
\hline
\end{tabular}

Dos objetivos propostos pelas IES para a formação de supervisores, é possível inferir que há uma conceção de formar profissionais capazes de promoverem intervenções no campo da educação, terreno para transformação e melhoria de práticas instituídas a partir do conhecimento construído no percurso de formação a que foram submetidos.

A escolha dos verbos usados para indicação dos objetivos a alcançar, tais como: formar, contribuir, aplicar, integrar, intervir, implementar, desenvolver, perspetivar, proporcionar,ratifica a ideia de uma formação que atribui a esse profissional um estatuto de quem é autorizado, por possuir uma expertise, a desempenhar ativamente a sua prática supervisiva já que passa a deter essa epistemologia que possibilita transformações no terreno. Esta ideia vai ao encontro do que Vieira (2009) sustenta ao atribuir à supervisão uma componente conceptual e outra experiencial, traduzidas em práxis, o que possibilita transformar a atividade pedagógica desenvolvida por professores, qualificando a sua própria ação. 


\section{autêntica}

DOI https://doi.org/10.31639/rbpfp.v12i24.314

Articulação entre desenvolvimento profissional e interação colaborativa

Quadro 3 - Instituições e objetivos na articulação entre desenvolvimento profissional e interação colaborativa

\begin{tabular}{|c|c|}
\hline DAS INSTITUIÇÕES & DOS OBJETIVOS \\
\hline \multirow{2}{*}{$\begin{array}{l}\text { Universidade do Minho - Instituto } \\
\text { de Educação }\end{array}$} & $\begin{array}{l}\text { Desenvolver capacidades necessárias para o envolvimento em } \\
\text { contexto de investigação empírica e/ou de desenvolvimento. }\end{array}$ \\
\hline & $\begin{array}{l}\text { Desenvolver competências de aprendizagem ao longo da vida, } \\
\text { de um modo autónomo, na sua área de especialização. }\end{array}$ \\
\hline $\begin{array}{l}\text { Universidade Católica Portuguesa } \\
\text { - Porto }\end{array}$ & $\begin{array}{c}\text { Reforçar a capacidade de intervenção de técnicos da educação } \\
\text { e de educadores e professores em áreas críticas relacionadas } \\
\text { com a educação, contribuindo para melhorar os processos e os } \\
\text { resultados sociais e educativos. }\end{array}$ \\
\hline \multirow{3}{*}{ Universidade Lusófona do Porto } & $\begin{array}{l}\text { Preparar e qualificar formadores, profissionais e investigadores } \\
\text { para a liderança e o exercício de funções nos domínios da } \\
\text { administração educacional, da supervisão pedagógica e formação } \\
\text { de formadores e na educação e formação de adultos. }\end{array}$ \\
\hline & $\begin{array}{c}\text { Promover um espaço multicultural de reflexão e de investigação } \\
\text { centrado na ação e intervenção educativas, numa perspetiva } \\
\text { integradora de diferentes metodologias, temáticas e } \\
\text { intervenientes. }\end{array}$ \\
\hline & $\begin{array}{l}\text { Reforçar a capacidade de intervenção de cada técnico de } \\
\text { educação, professor e orientador nas áreas de formação. }\end{array}$ \\
\hline Universdade de Évora & $\begin{array}{l}\text { Proporcionar formação acrescida, especializada e sustentada na } \\
\text { investigação, a profissionais da educação e do ensino, exercendo, } \\
\text { em particular, funções de coordenação e supervisão em } \\
\text { estruturas intermédias de jardins de infância, escolas dos ensinos } \\
\text { básico e secundário e outras valências do sistema educativo. }\end{array}$ \\
\hline Universidade de Coimbra & $\begin{array}{l}\text { Desenvolver uma consciência ética e deontológica de funções } \\
\text { docente e da formação em geral. }\end{array}$ \\
\hline \multirow{2}{*}{$\begin{array}{l}\text { Universidade de Trás-os-Montes } \\
\quad \text { e Alto Douro (UTAD) }\end{array}$} & $\begin{array}{l}\text { Aprofundar conhecimentos científicos e competências no domí- } \\
\text { nio das Ciências da Educação com particular relevo para as áreas } \\
\text { de especialização, com vista ao desenvolvimento científico ou à } \\
\text { aplicação em contexto de trabalho. }\end{array}$ \\
\hline & $\begin{array}{l}\text { Formar profissionais com capacidade investigativa e de } \\
\text { intervenção educacional, particularmente em áreas específicas } \\
\text { das Ciências da Educação. }\end{array}$ \\
\hline
\end{tabular}




\section{autêntica}

DOI https://doi.org/10.31639/rbpfp.v12i24.314

\begin{tabular}{|c|c|}
\hline \multirow{2}{*}{ Universidade da Madeira } & $\begin{array}{l}\text { Visar, de uma maneira geral, apetrechar o sistema educativo } \\
\text { regional e nacional, de formadores de professores e supervisores } \\
\text { pedagógicos, a fim de intervirem, enquanto docentes em } \\
\text { estabelecimentos de educação e ensino, na sua autoformação } \\
\text { e na formação inicial e contínua de professores. }\end{array}$ \\
\hline & $\begin{array}{l}\text { Visar também de maneira especial formar uma bolsa de } \\
\text { formadores de professores (orientadores de estágio e } \\
\text { professores cooperantes da prática pedagógica) para uma } \\
\text { supervisão da iniciação à prática profissional dos alunos da } \\
\text { Licenciatura em Educação Básica e dos Mestrados de educação } \\
\text { e ensino da Universidade da Madeira. }\end{array}$ \\
\hline \multirow{4}{*}{$\begin{array}{l}\text { Instituto Politécnico de Castelo } \\
\text { Branco - ESSE }\end{array}$} & $\begin{array}{l}\text { Aperfeiçoar competências ao nível da implementação, inovação } \\
\text { e avaliação curricular na área específica de ensino. }\end{array}$ \\
\hline & $\begin{array}{l}\text { Desenvolver capacidades para conceber, implementar } \\
\text { e avaliar projetos a diferentes níveis educativos. }\end{array}$ \\
\hline & Coordenar processos de autoavaliação da organização educativa. \\
\hline & $\begin{array}{l}\text { Desenvolver a autonomia profissional inserida num processo } \\
\qquad \text { de aprendizagem ao longo da vida. }\end{array}$ \\
\hline \multirow{4}{*}{$\begin{array}{l}\text { Instituto Politécnico de Viana } \\
\text { do Castelo - ESSE }\end{array}$} & $\begin{array}{l}\text { Proporcionar uma formação de nível avançado no âmbito da } \\
\text { Supervisão pedagógica a todos os profissionais de ensino. }\end{array}$ \\
\hline & $\begin{array}{l}\text { Fomentar a aquisição e desenvolvimento de saberes, } \\
\text { competências e experiências naárea da supervisão pedagógica. }\end{array}$ \\
\hline & $\begin{array}{c}\text { Desenvolver competências, capacidades e atitudes de reflexão } \\
\text { e análise crítica, de inovação e de investigação sobre supervisão } \\
\text { pedagógica no quadro da formação de professores, e em } \\
\text { relação aos desafios, processos e comportamentos do quotidiano } \\
\text { profissional. }\end{array}$ \\
\hline & $\begin{array}{c}\text { Contribuir para o favorecimento de um clima positivo nas escolas, } \\
\text { e de um maior grau de comunicação, abertura e colaboração dos } \\
\text { educadores e professores entre si. }\end{array}$ \\
\hline $\begin{array}{l}\text { Instituto Politécnico do Porto - } \\
\text { Escola Superior de Educação }\end{array}$ & $\begin{array}{c}\text { Habilitar os estudantes para o exercício da supervisão pedagógica } \\
\text { e institucional da escola e do jardim de infância. }\end{array}$ \\
\hline
\end{tabular}

No que tange aos objetivos, e sua relação com os conceitos de desenvolvimento profissional e de interação colaborativa, verifica-se a presença de verbos que sinalizam ações que poderão viabilizar tal movimento: agir e interagir para o desenvolvimento profissional do outro ou para o seu próprio. Assim, temos, por 


\section{autêntica}

exemplo: desenvolver capacidades, desenvolver competências de aprendizagem, reforçar a capacidade de intervenção, desenvolver competências, capacidades e atitudes de reflexão e análise crítica, de inovação e de investigação,contribuir para o favorecimento de um clima positivo nas escolas, promover um espaço multicultural de reflexão e de investigação centrado na ação e intervenção educativas, fomentar a aquisição e desenvolvimento de saberes, competências e experiências, coordenar processos de autoavaliação, enfim, verbos que representam ações que podem levar à conquista do próprio desenvolvimento profissional e/ou ao dos pares, como também de interação, considerando como pressuposto o investimento no desenvolvimento de competências e na construção de espaços de diálogo para melhoria dos processos dos sujeitos envolvidos na ação educacional. Nesse sentido,

Confirmam-se, então, a idéia e o princípio de que o supervisor não é um "técnico" encarregado da eficiência do trabalho e, muito menos, um "controlador" de "produção"; sua função e seu papel assumem uma posição social e politicamente maior, de líder, de coordenador, que estimula o grupo à compreensão - contextualizada e crítica - de suas ações e, também, de seus direitos (RANGEL, 2005, p. 150-151 - grifo da autora).

O profissional supervisor nesta perspetiva formativa assume o papel de formador, de líder, de articulador, de assessor colaborativo, de dinamizador, de mediador, de coordenador, de facilitador, de líder de comunidades aprendentes, de peça vitaltal como defendido por autores como Rangel (2005, 2009, 2010), Alarcão (2010a, 2010b), Alarcão e Tavares (2010), Imbernón $(2009,2010)$ em espaços noterreno da prática pedagógica que se podem aproximar dos denominados Ateliês de formação continuada e em serviço de professores (MACHADO, 2015).

Nesta linha, esta formação proposta aos supervisores alinha-se com o que Alarcão e Tavares defendem:

Pretendemos que eles [supervisores] sejam peças vitais numa escola constituída como uma organização que aprende ao longo de sua vida, porque sabe interpretar a sua história passada, ler a sua realidade presente e planificar o seu futuro na flexibilidade que só a abertura ecológica e o sentido de missão institucional conseguem proporcionar. Uma escola com memória, ambição, projecto(ALARCÃO; TAVARES, 2010, p.148).

O reconhecimento do lugar ocupado pelo supervisor como peça vital está expresso nos objetivos apresentados nos Planos curriculares dos cursos de Supervisão ao nível de Metrado das IES portuguesas de modo a atribuir a esse profissional, por meio da sua formação, uma expertise capaz de contribuir para a construção, individual e coletiva, de uma epistemologia da prática supervisa.

Supervisão e construção de uma epistemologia da prática 


\section{autêntica}

DOI https://doi.org/10.31639/rbpfp.v12i24.314

Quadro 4 - Instituições e objetivos na supervisão e construção de uma epistemologia da prática

\begin{tabular}{|c|c|}
\hline DAS INSTITUIÇÕES & DOS OBJETIVOS \\
\hline $\begin{array}{l}\text { Universidade de Lisboa - } \\
\text { Instituto de Educação }\end{array}$ & $\begin{array}{l}\text { Visar o desenvolvimento e aprofundamento de conhecimentos e } \\
\text { competências na área da Supervisão e Orientação da Prática } \\
\text { Profissional com o duplo propósito de promover o aperfeiçoamento } \\
\text { da prática profissional dos formandos e a aquisição de competências } \\
\text { no âmbito da investigação e realização de projetos. }\end{array}$ \\
\hline \multirow{3}{*}{$\begin{array}{l}\text { Universidade do Minho - } \\
\text { Instituto de Educação }\end{array}$} & $\begin{array}{c}\text { Elaborar projetos de investigação pertinentes e relevantes para a sua } \\
\text { área de especialização. }\end{array}$ \\
\hline & $\begin{array}{l}\text { Comunicar conhecimentos e raciocínios a eles subjacentes, quer a } \\
\text { especialistas, quer a não especialistas, de uma forma clara e sem } \\
\text { ambiguidades. }\end{array}$ \\
\hline & Pronunciar-se fundamentadamente sobre questões educacionais. \\
\hline \multirow{2}{*}{$\begin{array}{l}\text { Universidade Lusófona do } \\
\text { Porto }\end{array}$} & $\begin{array}{l}\text { Contribuir para o aprofundamento de conhecimentos e competências } \\
\text { num quadro teórico amplo e atual. }\end{array}$ \\
\hline & $\begin{array}{l}\text { Desenvolver conhecimentos sobre métodos e técnicas que permitam } \\
\text { a pesquisa no campo da educação e formação de adultos. }\end{array}$ \\
\hline \multirow[t]{2}{*}{ Universidade de Coimbra } & $\begin{array}{l}\text { Conhecer enquadramentos ideológico-representacionais, } \\
\text { normativo-legais e teórico-empíricos que permitam compreender } \\
\text { e estruturar o ensino e a formação de professores. }\end{array}$ \\
\hline & $\begin{array}{c}\text { Compreender os paradigmas da avaliação do ensino e da formação } \\
\text { de professores. }\end{array}$ \\
\hline \multirow{2}{*}{$\begin{array}{l}\text { Instituto Politécnico de } \\
\text { Castelo Branco - ESE }\end{array}$} & $\begin{array}{c}\text { Conhecer teorias e modelos de supervisão pedagógica e das } \\
\text { organizações educativas. }\end{array}$ \\
\hline & $\begin{array}{l}\text { Desenvolver conhecimentos, atitudes e competências que } \\
\text { permitam investigar e assumir criticamente tarefas de supervisão } \\
\text { e de avaliação. }\end{array}$ \\
\hline $\begin{array}{l}\text { Instituto Politécnico do Porto - } \\
\text { Escola Superior de Educação }\end{array}$ & $\begin{array}{c}\text { Contribuir para o desenvolvimento de um quadro concetual e } \\
\text { metodológico que sustente uma cultura de Supervisão na escola } \\
\text { e no jardim de infância. }\end{array}$ \\
\hline
\end{tabular}

No que tange à supervisão como campo do conhecimento e à contrução de uma epistemologia da prática supervisiva, percebemos a vontade de validação de um processo de construção do conhecimento num dado campo da educação que ocorre a partir de um alinhamento e de um aprofundamento de questões teóricas que se traduzem na prática do fazer supervisivo-pedagógico, que tem na sua essência um compromisso 


\section{autêntica}

ético com o reconhecimento, o alargamento e, especialmente, com a validação do próprio conhecimento concretizado em ações. Essa validação do conhecimento construído decorre do processo de envolvimento dos sujeitos com o objeto foco da ação supervisiva, nesse movimento teórico-prático, a transformação dos sujeitos e das práticas.

Interessa apontar ainda as potencialidades de formação de supervisores descritos por meio de verbos que sinalizam ações que viabilizam e atribuem sentido à epistemologia da prática supervisiva, tais como: promover, elaborar,comunicar, assumir, investigar, desenvolver, pronunciar, estruturar, conhecer, compreender, visar, contribuir. Os objetivos descritos por meio desses verbos apontam para um fortalecimento e um aprofundamento de conhecimentos, paradigmas, enquadramentos e teorias imprescindíveis à atividade supervisiva que cada vez mais exige do profissional supervisor a construção de uma epistemologia da prática supervisiva. Por outro lado, podemos também perceber um movimento da teoria à prática para intervenção fundamentada e transformadora, capaz de validar a atividade desempenhada por profissionais supervisores.

Ainda podemos identificar que as finalidades dos 13 cursos apresentam um conjunto de verbos, cuja seleção reenvia a uma conceção de formação na área da supervisão. Conforme resultados sintetizados no quadro 5 , os verbos desenvolver, contribuir, proporcionar e visar surgem com maior destaque.

Quadro 5 - Frequência de verbos apresentados neste estudo nos objetivos das instituições

\begin{tabular}{|c|c|}
\hline Verbo (s) & $\begin{array}{c}\mathbf{N}^{\mathbf{0}} \text { de } \\
\text { Referências }\end{array}$ \\
\hline Desenvolver & 10 \\
\hline Contribuir & 06 \\
\hline proporcionar, visar & 03 \\
\hline formar, implementar, perspetivar, reforçar, compreender, conhecer, \\
intervir, promover \\
\hline $\begin{array}{c}\text { aplicar, integrar, refletir, melhorar, preparar, qualificar, aprofundar, investigar, } \\
\text { assumir, estruturar, aperfeiçoar, apetrechar, conceber, avaliar, coordenar, } \\
\text { fomentar, elaborar, comunicar, pronunciar-se, habilitar }\end{array}$ \\
02 \\
\hline
\end{tabular}

É interessante perceber que as escolhas dos verbos utilizados na descrição dos objetivos do curso têm estreita relação com a própria concepção não só de formação desse profissional, mas, e especialmente, de trabalho, já que sua atuação exige tais ações. 


\section{autêntica}

DOI https://doi.org/10.31639/rbpfp.v12i24.314

\section{Considerações finais}

A partir deste estudo, podemos afirmar quehá necessidade de aprofundamento da temática apresentada com análises mais detalhadas das unidades curriculares que compõem os Planos de Estudos. As estratégias de formação concebidas e postas em prática pelos atores educativos na área da supervisão, a análise realizada às finalidades gerais dos cursos de Mestrado evidenciam uma conceção de supervisão transformadora e emancipatória, perseguindo a finalidade de proporcionar espaços de desenvolvimento profissional docente para a construção de conhecimento sobre a prática supervisiva e para a promoção futura de uma atuação que requer interação colaborativa.

Essa formação revela ainda uma preocupação em alargar o campo de ação dos supervisores no sentido de atribuir à função por eles desempenhada uma dimensão que reconhece uma expertise própria da profissão articulada ao aprofundamento do conhecimento especifico e geral no campo educacional com vista à melhoria da formação e do trabalho docentes. 


\section{autêntica}

DOI https://doi.org/10.31639/rbpfp.v12i24.314

\section{Referências}

ALARCÃO, Isabel. Desenvolvimento profissional, interação colaborativa e supervisão. In:MACHADO, Joaquim; ALVES, José Matias(Coords.).Coordenação, supervisão e liderança: escolas, projetos e aprendizagens. E-book. Porto: Universidade Católica Editora, 2014, p. 22-35. ISBN 978.989.8366.78-8.

ALARCÃO, Isabel. Professores reflexivos em uma escola reflexiva.7 ed. São Paulo: Cortez, v. 8 - Coleção questões de nossa época, 2010a.

ALARCÃO, Isabel. Do olhar supervisivo ao olhar sobre a supervisão. In Mary Rangel (Org.). Supervisão pedagógica:princípios e práticas. Campinas, SP: Papirus - Coleção Magistério: Formação e trabalho pedagógico, 2010b, p. 11-55.

ALARCÃO, Isabel;TAVARES, José. Supervisão da Prática Pedagógica. Uma perspectiva de desenvolvimento e aprendizagem. 2 ed. Coimbra: Almedina, 2010.

IMBERNÓN, Francisco. Formação permanente do professorado: novas tendências. São Paulo: Cortez, 2009.

IMBERNÓN, Francisco. Formação continuada de professores. Tradução Juliana dos Santos Padilha. Porto Alegre: Artmed, 2010.

MACHADO, Jane do Carmo. O discurso de professores: uma contribuição para a formação continuada e em serviço de professores. Trabalho de conclusão de estudos de Tópicos especiais em LSC - subjetividade e cultura: leituras de Bakhtin do Curso de Doutorado em Educação da Universidade Federal Fluminense. Niterói, RJ: PPGEUFF, 2012.

MACHADO, Jane do Carmo. Os Ateliês de formação na escola: uma articulação com o trabalho docente. Anais do XII Congresso Nacional de Educação - Educere - Formação de Professores, complexidade e trabalho docente, 2015, p. 34714- 34727.Disponível em:<https://educere.bruc.com.br/arquivo/pdf2015/17158_7487. pdf>. ISSN 2176-1396.

PORTUGAL.Decreto-Lei $n^{\circ}$ 74/2006 - Alterado pelo Decreto-Lei no 107/2008, de 25 de junho, pelo Decreto-Lei $n^{\circ}$ 230/2009, de 14 de setembro, pelo Decreto-Lei no 115/2013, de 7 de agosto, pelo Decreto-Lei n 63/2016, de 13 de setembro e pelo Decreto-Lei n 65/2018, de 16 de agosto. Diário da República. Diário da República, 1. ${ }^{a}$ série A - N. ${ }^{\circ} 60-24$ de março de 2006. Disponível em:<https://dre.pt/application/file/a/671482>.

PORTUGAL. Decreto-Lei n 79/2014. Diário da República. Diário da República, 1. a série - N. $92-14$ de maio de 2014. Disponível em<https://dre.pt/application/file/a/25344968>.

RANGEL, Mary. Considerações sobre o papel do supervisor, como especialista em educação, na América Latina. In: RANGEL, Mary; SILVA JR., Celestino Alves da. (Orgs.). Nove olhares sobre a supervisão. 11 ed. São Paulo: Papirus - Coleção Magistério: Formação e trabalho pedagógico, 2005,p. 147- 161. .

RANGEL, Mary. Supervisão e orientação educacional: concepções e práticas conjuntas. In:RANGEL, Mary (Org.). Supervisão e gestão na escola: conceitos e práticas de mediação. 2 ed. Campinas, SP: Papirus Coleção Magistério: Formação e trabalho pedagógico, 2009, p. 11-23. 


\section{autêntica}

DOI https://doi.org/10.31639/rbpfp.v12i24.314

RANGEL, Mary. O estudo como prática de supervisão. In:RANGEL, Mary (Org.). Supervisão pedagógica: princípios e práticas. Campinas, SP: Papirus- Coleção Magistério: Formação e trabalho pedagógico, 2010, p. 57-67.

SÁ-CHAVES, Idália. Formação, conhecimento e supervisão: Contributos nas áreas de formação de professores e de outros profissionais. Estudos temáticos 1, Universidade de Aveiro, 2011.

VIEIRA, Flávia. Para uma visão transformadora da Supervisão Pedagógica. Educ. Soc., Campinas, vol. 30, n. 106, p. 197-217, jan./abr., 2009. Disponível em:<http://www.scielo.br/pdf/es/v30n106/v30n106a10.pdf>.

VIEIRA, Flávia;MOREIRA, Maria Alfredo. Supervisão e avaliação do desempenho docente: para uma abordagem de orientação transformadora. Cadernos do CCAP, 1. Lisboa: Ministério da Educação - Conselho Científico para a Avaliação de Professores, 2011. Disponível em:<http://files. avaliacao-externa.webnode.pt/200000021-b8fb0b9f74/Caderno_CCAP_1-Supervisao.pdf>.

ZEICHNER, Ken. Repensando as conexões entre a formação na universidade e as experiências de campo na formação de professores em faculdades e universidades. Educação, Santa Maria, vol. 35, n. 3, p. 479-504, set./ dez., 2010.ISSN 1984-6444. Disponível em:<https://periodicos.ufsm. br/reveducacao/article/view/2357/1424>.

MACHADO, J. C.; ANDRADE, A. I.; NEVES, R.; Os planos curriculares de cursos em supervisão: um contributo para uma epistemologia da prática. Formação Docente - Revista Brasileira de Pesquisa sobre Formação de Professores. Belo Horizonte. Vol. 12, nº. 24 (p. 135-150) 31 ago. 2020 